\title{
The Effect of Fluxes on the Melt Quality of AlSi7MgCu Alloy
}

\author{
G. GYARMATI ${ }^{1}$, Gy. FegYVERnEKI ${ }^{2}$, T. MENDE ${ }^{3}$, M. ToKÁR ${ }^{4}$ \\ ${ }^{1}$ University of Miskolc, Faculty of Materials Science and Engineering, Foundry Institute, gygabor007@gmail.com \\ ${ }^{2}$ University of Miskolc, Faculty of Materials Science and Engineering, Foundry Institute, \\ gyorgy.fegyverneki@nemak.com \\ ${ }^{3}$ University of Miskolc, Faculty of Materials Science and Engineering, Institute of Physical Metallurgy, \\ Metalforming and Nanotechnology, tamas.mende@uni-miskolc.hu \\ ${ }^{4}$ University of Miskolc, Faculty of Materials Science and Engineering, Foundry Institute, monika.tokar@uni- \\ miskolc.hu
}

Abstract. The presence of inclusions such as oxides, carbides or refractory particles can be harmful to the mechanical and surface characteristics of castings. Inclusion-rich metals result in lower fluidity and feeding capability during casting. Nowadays, solid fluxes are widely used in foundries in order to reduce the inclusion content of aluminium melts. In this study, the effect of four different fluxes on the melt quality was studied. First, the inclusion content of the flux-treated melt, and then the properties of the fluxes (i.e. chemical composition and melting temperature) were examined.

\section{Introduction}

Inclusions are discontinuities of the material which are non-metallic or sometimes intermetallic phases embedded in a metallic matrix [1]. Inclusions can occur in the form of solid particles, films or liquid droplets in the molten alloys [2]. The quantity and type of inclusions in the melt are determined by the quality of charge and alloying materials, as well as the melting and melt handling processes. The most common inclusions in aluminium alloys are non-metallic compounds: oxides, nitrides, carbides, and borides. Inclusions can be observed in the form of single particles, clusters and agglomerates [35]. Inclusions reduce mechanical properties by detracting from the effective cross-sectional area when stress is applied and because of the concentration of stresses at the inclusion interface [6, 7]. Inclusions in the melt can negatively influence melt fluidity and prevent interdendritic feeding $[8,9]$.

Flux treatment usually consists of the addition of a solid blend of inorganic compounds to the melt. These compounds may perform several functions, such as the removal of non-metallic impurities from the melt, the protection of the melt surface or the refinement and/or degassing of the molten alloy [10, 11]. The effect of fluxes is determined by their chemical composition, morphology, added quantity, as well as the temperature of the melt and the method of flux addition. It is important that the compounds in the fluxes should be able to form low-melting high-fluidity mixtures at working temperature $[12,13]$. Generally, the base flux components can be classified into four major groups 
based on their primary influence on the mixture: chlorides, fluorides, solvents of aluminium oxides and oxidizing compounds. Chlorides are mostly used for their fluidizing effects, but they can also be used as fillers and carriers. Fluoride salts act as surfactants and wet the interface between the inclusions and the liquid metal. Therefore, fluoride salts promote inclusion separation and metal coalescence. Oxidizing compounds are used to accelerate exothermic chemical reactions, which stimulate the coalescence of larger aluminium droplets trapped in the dross. Thus, the recovery of useful metal is facilitated. On the other hand, the heat released during the reactions promotes the interfacial reactions between the molten flux and the inclusions in the melt [10-12].

In this study, the effects of different fluxes on the inclusion content of an aluminium alloy melt were compared. In order to find the reason for differences in melt cleaning efficiency, the chemical composition and thermal properties of the flux blends were investigated.

\section{Experimental Procedure}

Melt treatments consisting of rotary degassing with $\mathrm{N}_{2}$ gas and flux addition were executed on an Al7Si-0.4Mg-0.5Cu alloy melt using four different fluxes $(A, B, C$ and $D)$. Each flux was used in 8 treatment cycles. The quantity of metal treated in one cycle was approximately 1 ton. The metal was melted in a stack smelter then transported by a transport ladle to a resistance heated holding furnace where the melt treatments were performed (Figure 1). In each case, the melt was poured onto a lesser quantity of melt (ca. $200 \mathrm{~kg}$ ) which remained in the holding furnace from the previous cycle. The treatment parameters and the quantity of flux added $(400 \mathrm{~g})$ were the same in each cycle. The $\mathrm{N}_{2}$ gas flow rate was $20 \mathrm{~L} / \mathrm{min}$; the rotor revolution was $500 \mathrm{RPM}$ during vortex formation and $250 \mathrm{RPM}$ in the degassing phase. The treatment time was 10 minutes in each case. The molten metal temperature in the holding furnace was maintained between $740{ }^{\circ} \mathrm{C}$ and $750{ }^{\circ} \mathrm{C}$.
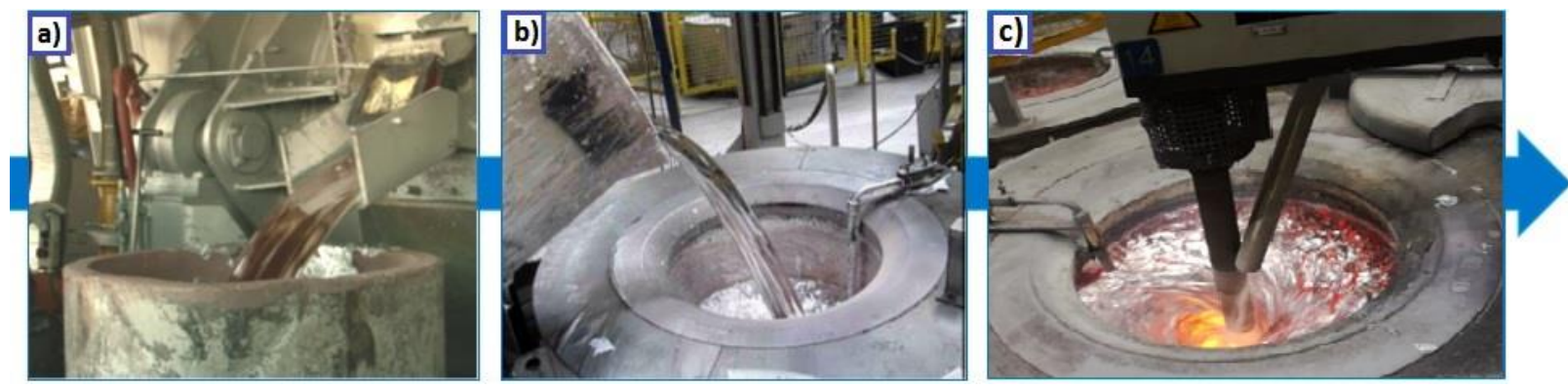

Figure 1. The stages of melt preparation: a) pouring from melting furnace, b) melt transport to holding furnace, and c) melt processing.

The inclusion content of the melts treated with different fluxes was investigated by the evaluation of K-mould samples, which were prepared in a gravity die called K-mould. The sample itself is a flat plate with four notches that act as fracture points. The fracture surface of samples can be examined either by visual inspection or with a microscope. Based on the number of inclusions, a K-value can be determined which can be used for the quantitative characterization of the melt purity (Equation 1).

$$
\mathrm{K}=\frac{\mathrm{S}}{\mathrm{n}}
$$


where $\boldsymbol{K}$ is the K-mould value, $\boldsymbol{n}$ is the number of examined samples, and $\boldsymbol{S}$ is the total number of inclusions found in $\boldsymbol{n}$ pieces $[14,15]$. The effect of different fluxes on the melt purity was evaluated using the comparison of the K-values determined before and after the melt treatments. The percentage of change in K-values ( $\Delta K[\%])$ was calculated using Equation 2.

$$
\Delta \mathrm{K}=\frac{\mathrm{K}_{2}-\mathrm{K}_{1}}{\mathrm{~K}_{1}} \cdot 100
$$

where $\boldsymbol{K}_{\mathbf{1}}$ is the $\mathrm{K}$-value determined before the melt treatment and $\boldsymbol{K}_{\mathbf{2}}$ is the K-value determined after the melt treatment. During each melt preparation, K-mould samples were cast 3 times; the number of samples cast at once was 5 . During the investigated 32 cycles (8 cycle/flux blend), $480 \mathrm{~K}$-mould samples were cast. The fracture surface of K-mould samples was inspected with a stereomicroscope at a magnification of 25X. The inclusions found on the fracture surfaces were examined with scanning electron microscope (SEM) combined with energy dispersive X-ray spectroscopy (EDS analysis). In each case, the first K-mould samples were prepared from the melt in the transport ladle. After the melt was poured into the holding furnace and the produced wet dross was removed, another series of $\mathrm{K}$ mould samples were prepared. The third series of samples were cast after skimming, following the fluxing and degassing treatment.

The elemental composition of the fluxes was examined with EDS analysis. The thermal properties of the fluxes were investigated with derivatographic measurements. The derivatograph is capable of performing differential thermal analysis (DTA) and thermogravimetric (TG) measurements on the same sample at the same time. During the investigations, a MOM Derivatograph-C apparatus was used with a platinum crucible, the rate of heating was $10{ }^{\circ} \mathrm{C} / \mathrm{min}$, the maximum temperature of the measurement was $1000{ }^{\circ} \mathrm{C} . \alpha-\mathrm{Al}_{2} \mathrm{O}_{3}$ was used as reference material, the mass of each flux samples was $150 \mathrm{mg}$.

\section{Results and Discussion}

\subsection{Inclusion Analysis}

The average K-values of the melts at the different stages of melt preparation can be observed in Figure 2.

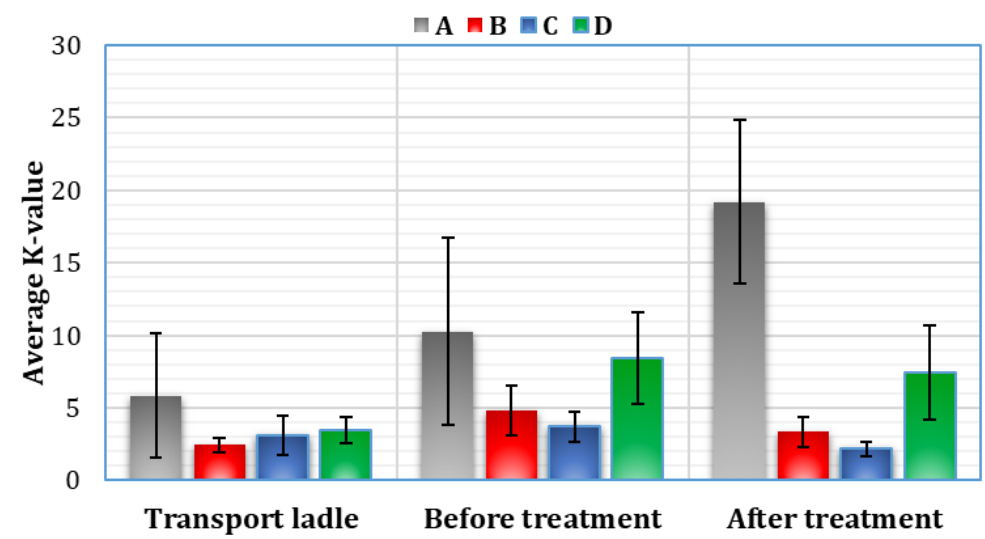

Figure 2. Average $K$-values at the different stages of melt preparation 
It can be seen that the melts had different inclusion contents even in the transport ladle which was the result of the differences in the quality of charge materials. In each case, the melt in the transport ladle was poured onto a small quantity of melt remaining in the holding furnace from the previous cycle. Thus, the inclusion content of the melt was influenced by the quality of the residual melt. This way, the applied flux blends had an indirect effect on the average K-values of the melts even before the treatments were carried out. The average $\Delta \mathrm{K}$ values for each flux blends are illustrated in Figure 3 .

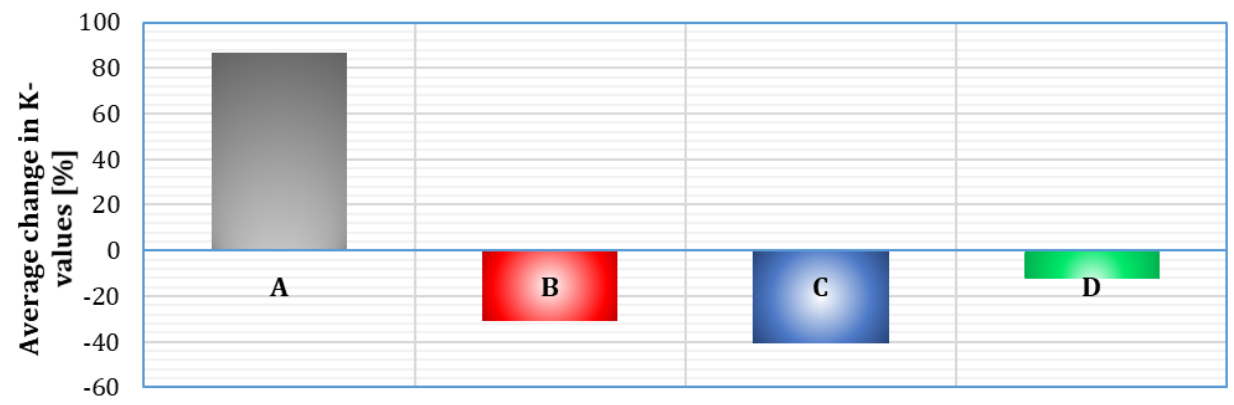

Figure 3. The average change in $K$-values $(\Delta K)$

The treatments executed with flux $C$ were the most effective in reducing the K-values and flux $B$ was the second most efficient. Flux blend $A$ had the poorest results. The melt treatments performed with flux $A$ resulted in the increased inclusion content of the melt, which caused a positive change in the average K-value. An example of inclusion found during the examination of K-mould samples can be seen in Figure 4.

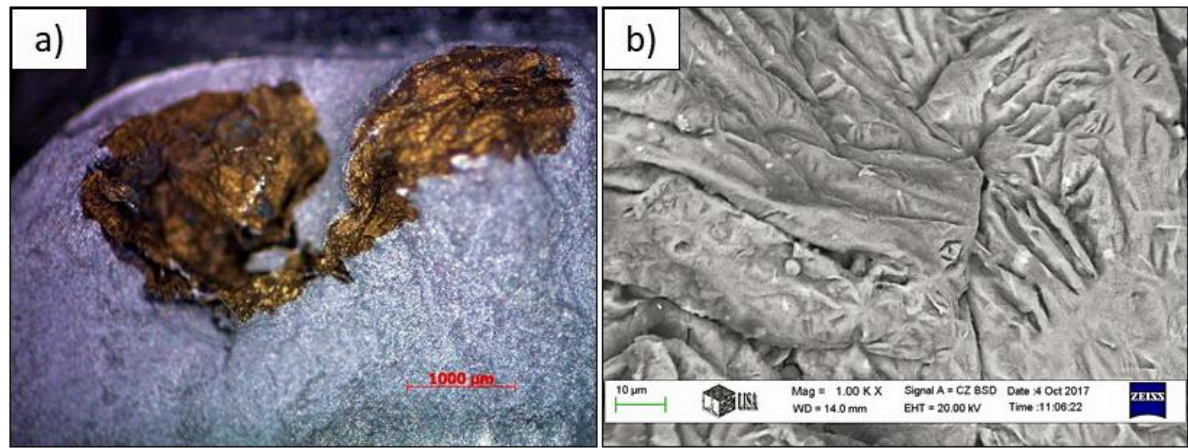

Figure 4. Inclusion found on a fracture surface of a K-mould specimen: a) microscopic and b) SEM image

In most cases, creased film-like inclusions were found on the fracture surfaces. Based on the EDS analysis, in most cases, the inclusions had significant oxygen and nitrogen content. Therefore, the inclusions found are probably nonmetallic compounds like $\mathrm{Al}_{2} \mathrm{O}_{3}, \mathrm{AlN}$ and $\mathrm{MgO} \cdot \mathrm{Al}_{2} \mathrm{O}_{3}$.

\subsection{Properties of Fluxes}

The elemental composition of fluxes measured with energy dispersive X-ray spectrometer (EDS) and the SEM images of flux grains are shown in Figure 5. The compositions presented were measured on the surface area of the flux grains. Elemental composition values of flux $D$ presented in Figure 5. were measured in case of three different grain. Elemental composition measurements on different flux grains were executed in case of flux $A, B$ and $C$. It was found, that the measured composition values are 
almost identical. Therefore, the flux grains have consistent chemical composition. As it can be seen in Figure 5., the grains of flux $D$ have significantly different composition values, which is a common attribute of powder fluxes according to the literature [12]. The inhomogeneity of the chemical composition of flux $D$ could be the main reason for the lower $\Delta \mathrm{K}$ values and thus the lower efficiency of melt cleaning.

The measured elemental composition values can be used to predict the quality and quantity of basic flux components like chlorides, fluorides and oxidizing compounds. Based on the chlorine and sodium content of flux $A$, the grains mainly consist of $\mathrm{NaCl}$. During the analysis there was no detectable amount of fluorine in the grains, therefore probably there are no fluorides in flux $A$. The absence of fluorides could be one of the reasons for the inefficiency of this flux regarding inclusion removal. Based on the fluorine and oxygen content of flux $B$, the flux is relatively richer in fluorides and oxidizing compounds. Flux $C$ contains the highest amount of oxidizing compounds, but the fluorine and thus the fluoride content of this flux is significantly lower than in the case of flux $B$. By the comparison of the measured K-values and the elemental composition of fluxes it can be concluded that the more effective fluxes ( $B$ and $C$ ) contain reactive components (like oxidizing compounds and fluorides) at higher concentration values and their grains have consistent chemical composition.

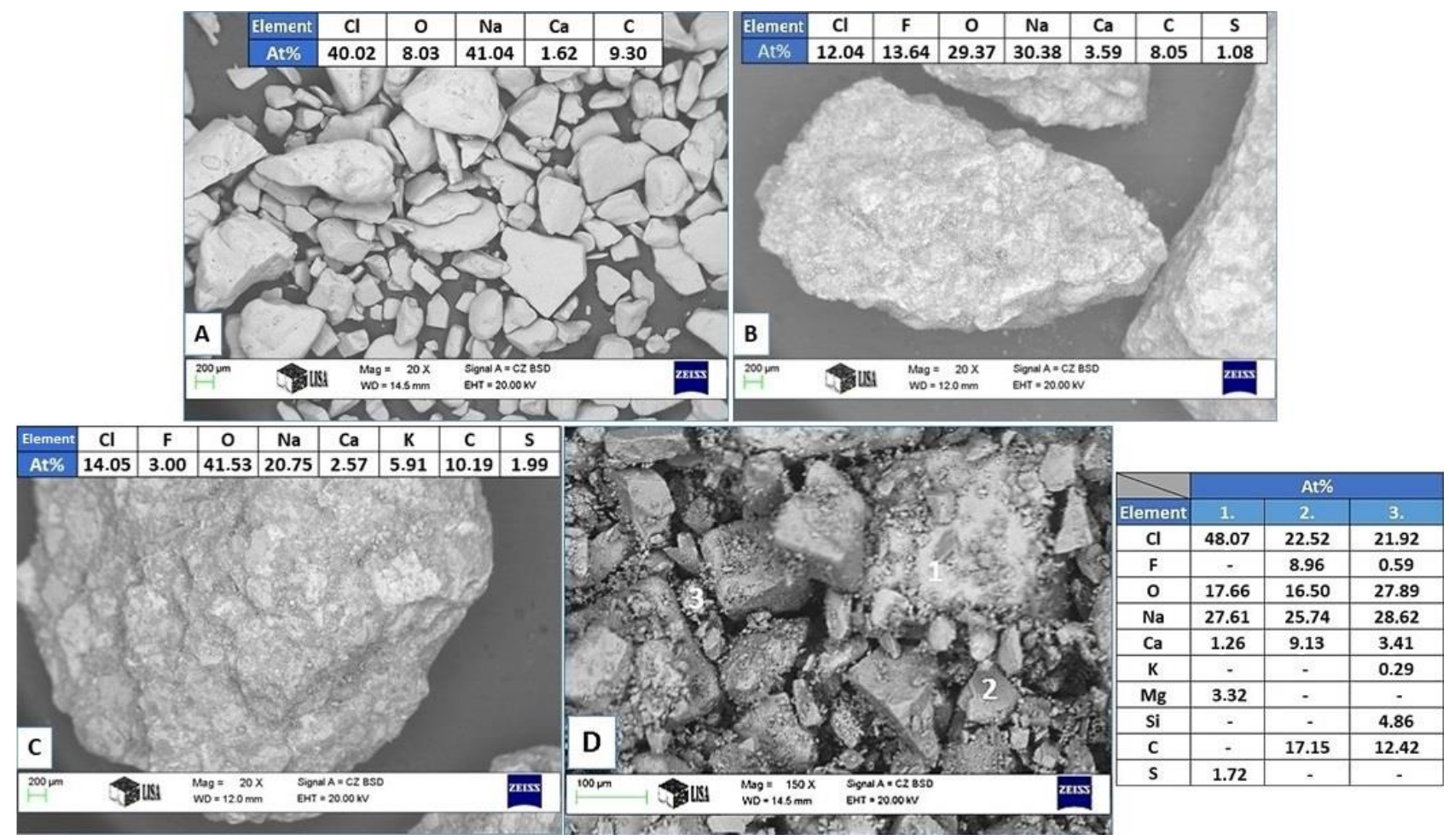

Figure 5. The SEM images and elemental composition of flux grains

As it can be seen in Figure 5. the grain sizes of flux A and D is significantly smaller than the other two fluxes since they are powder fluxes while flux B and C are granular. According to R. Gallo and D. Neff [12], granular fluxes are more efficient regarding melt cleaning because of the consistency of their chemical composition. This statement is in agreement with the results of the present study. 
With the aid of derivatographic measurements, the melting temperature of fluxes can be determined, which is an important property that significantly influences the melt cleaning efficiency. The evaluation process of the measured data is described via the analysis of DTA, TG and DTG curves recorded during the investigation of flux $C$ (Figure 6.). The DTA curve represents the temperature difference between the inert reference material and the flux sample during heating. Negative peaks on the DTA curve indicate endothermic reactions while positive peaks are the signs of exothermic reactions. The TG curve gives information about the percentage of the mass change of the flux sample. The DTG curve is the first derivative of the TG curve with respect to temperature. In order to find the melting temperature of the flux, the temperature values where strongly endothermic reactions occur according to the DTA curve, but no mass-change can be observed on the DTG curve should be identified. In case of flux $\mathrm{C}$, two significantly endothermic reactions with no mass-change can be identified. The first one is around $510^{\circ} \mathrm{C}$ and the second one is around $615^{\circ} \mathrm{C}$. The results indicate that the melting process of this flux starts at $510{ }^{\circ} \mathrm{C}$, and the melting of another phase with higher melting temperature takes place at $615^{\circ} \mathrm{C}$.

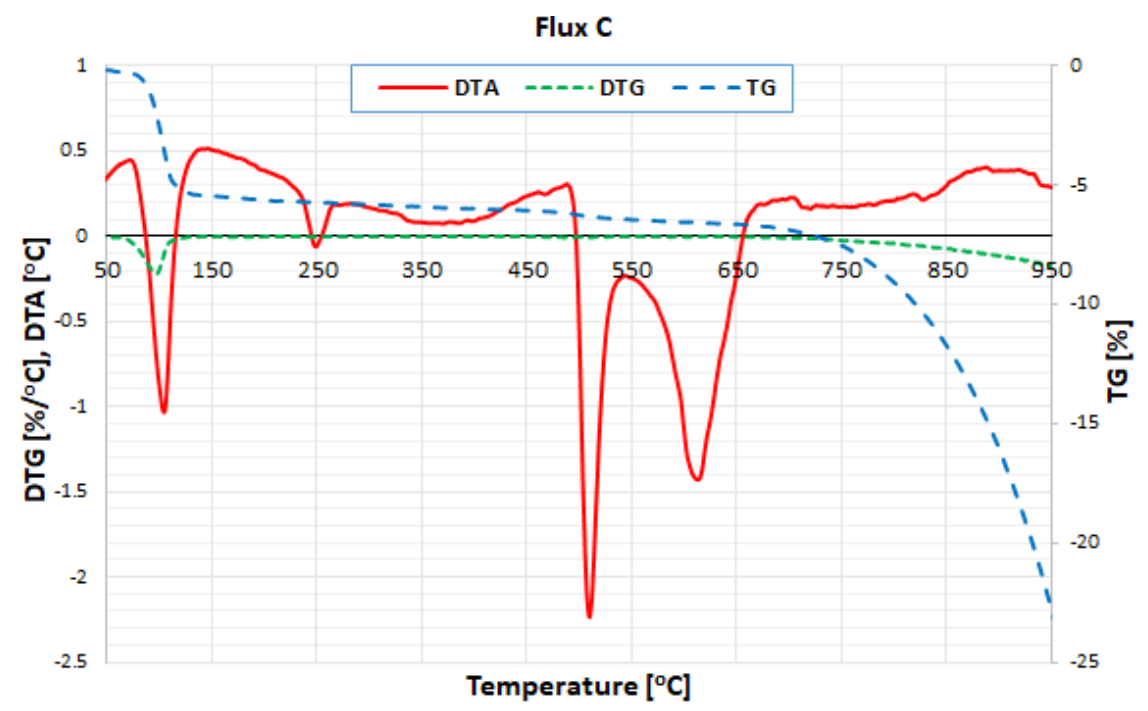

Figure 6. The derivatographic curves of flux $C$

With the aid of the evaluation process described above the melting temperature of each flux has been determined. Then, the temperature values were compared with the average change in $K$-values $(\Delta K)$ in order to find a relationship between the melt cleaning efficiency and the melting temperatures of the fluxes (Figure 7.). 


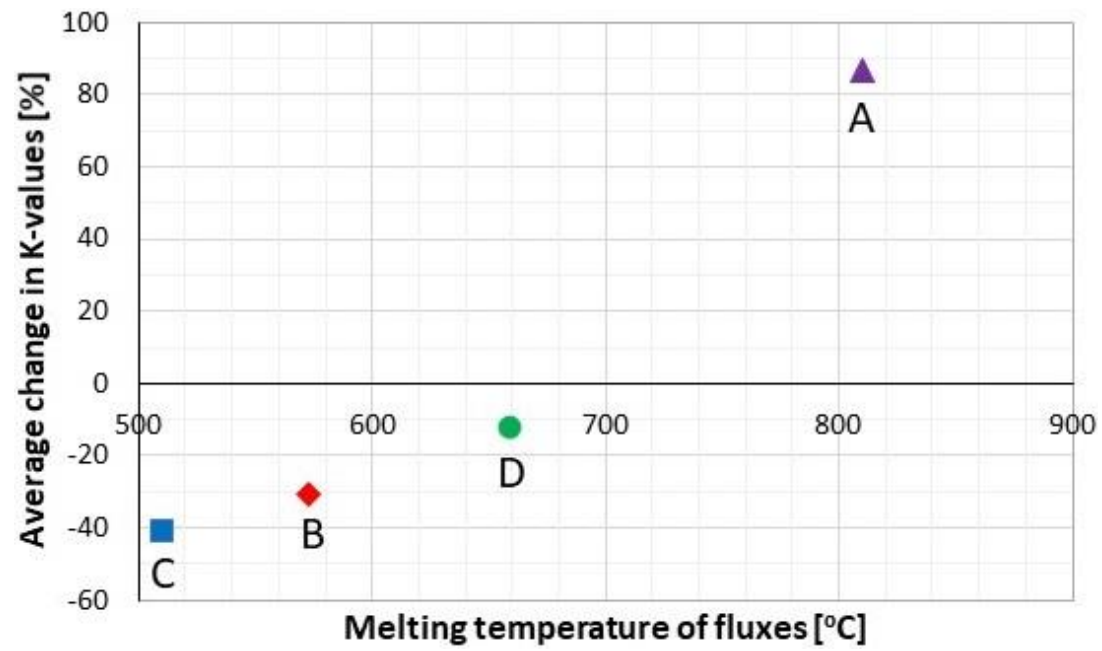

Figure 7. The comparison of melt cleaning efficiency and the melting temperature of fluxes

Based on Figure 7., it can be stated that in the case of the four fluxes investigated, the fluxes with lower melting temperature were more efficient regarding inclusion removal. According to 0 . Majidi et al. [16], the melt cleaning efficiency is dependent on the fluidity of molten fluxes. Since the viscosity of molten fluxes is temperature dependent, at a constant temperature the viscosity of molten fluxes with lower melting temperature is lower and their fluidity is better. During melt treatment, the molten fluxes with better fluidity can be dispersed more evenly in the molten metal which results in better melt cleaning efficiency. The described statement is in agreement with the results of the present study. Flux $A$ has the highest melting temperature which is actually higher than the maintained melt temperature $\left(740-750^{\circ} \mathrm{C}\right)$, therefore the grains of flux $A$ could not melt during melt processing. Since the flux grains were in solid state after addition, they were not capable of exposing any inclusion removing action, moreover, they contributed to the degradation of the melt quality via the entrainment of the surface oxide film of the melt during flux addition, which resulted in higher Kvalues. The main reason for the high melting temperature of flux $A$ could be its chemical composition, i. e. its high $\mathrm{NaCl}$ content (see Figure 5.).

\section{Summary}

From the results of the present study, it can be concluded that the melt cleaning efficiency of different fluxes is highly dependent on their chemical composition, morphology and melting temperature. Based on the results of $\mathrm{K}$-mould tests, flux $\mathrm{C}$ was the most effective in inclusion removal. The more effective fluxes (like $B$ and $C$ ) are granular, contain oxidizing compounds and fluorides at higher concentration values, their grains have a consistent chemical composition and they have significantly lower melting temperature than the temperature of the treated molten alloy.

\section{Acknowledgement}

The described study was carried out as part of the EFOP-3.6.1-16-2016-00011 "Younger and Renewing University - Innovative Knowledge City - institutional development of the University of 
International Journal of Engineering and Management Sciences (IJEMS) Vol. 4. (2019). No. 1 DOI: 10.21791/IJEMS.2019.1.46.

Miskolc aiming at intelligent specialisation" project implemented in the framework of the Szechenyi 2020 program. The realization of this project is supported by the European Union, co-financed by the European Social Fund.

\section{References}

[1] P. K. Trojan (2008) Inclusion-Forming Reactions, in: ASM Handbook Vol. 15.: Casting, ASM International. pp. 74-83.

[2] J. Morscheiser, P. Le Brun, M. Gökelma, M Badowski, T. Dang, S. Tewes (2015) Observation on Inclusion Settling by LiMCA and PoDFA Analysis in Aluminium Melts, International Aluminium Journal 91/4 pp. 56-61.

[3] R. Gallo (2017) I have Inclusions! Determining the Best Cost Saving Approach, Modern Casting 107/8 pp. 31-35.

[4] S. Shivkumar, L. Wang, D. Apelian (1991) Molten Metal Processing of Advanced Cast Aluminum Alloys, JOM 43/1 pp. 26-32.

[5] J. Campbell (2015) Complete Casting Handbook 2nd Edition - Metal Casting Processes, Metallurgy, Techniques and Design, Butterworth-Heinemann. pp. 3-90.

[6] L. Liu, F. H. Samuel (1998) Effect of Inclusions on the Tensile Properties of Al-7Si-0,35Mg (A356.2) Aluminium Casting Alloy, Journal of Materials Science 33/9 pp. 2269-2281.

[7] S. W. Hudson, D. Apelian (2016) Inclusion Detection in Molten Aluminum: Current Art and New Avenues for in Situ Analysis, International Journal of Metalcasting 10/ 3 pp. 315-321.

[8] M. Di Sabatino, L. Arnberg, S. Rorvik, A. Prestmo (2005) The Influence of Oxide Inclusions on the Fluidity of Al-7 wt.\%Si Alloy, Materials Science and Engineering A 413-414. pp. 272-276.

[9] M. di Sabatino, L. Arnberg, D. Apelian (2008) Progress on the Understanding of Fluidity of Aluminium Foundry Alloys, International Journal of Metalcasting 2/3 pp. 17-26.

[10] T. A, Utigard, K. Friesen, R. R. Roy, J. Lim, A. Silny, C. Dupuis (1998) The Properties and Uses of Fluxes in Molten Aluminum Processing, JOM 50/11 pp. 38-43.

[11] R. Gallo (2002) Development, Evaluation and Application of Solid Fluxes, Modern Casting 92/10 pp. 30-33.

[12] R. Gallo, D. Neff (2008) Aluminum Fluxes and Fluxing Practice, in: ASM Handbook Vol. 15.: Casting, ASM International, pp. 230-239.

[13] R. Colás, E. Velasco, S. Valtierra (2003) Castings. In: G. E. Totten, D. S. MacKenzie (Eds.), Handbook of Aluminum Vol. 1. - Physical Metallurgy and Processes, Marcel Dekker Inc., pp. 591641.

[14] S. Kitaoka (2001) Evaluation of the melt cleanliness by K-Mold test, In: Light Metals (Metaux Legers) 2001: International Symposium on Light Metals as held at the 40th Annual Conference of Metallurgists of CIM. Toronto, 26-29. Aug. 2001., pp. 13-24. 
International Journal of Engineering and Management Sciences (IJEMS) Vol. 4. (2019). No. 1

DOI: 10.21791/IJEMS.2019.1.46.

[15] M. Brůna, A. Sládek (2011) Hydrogen Analysis and Effect of Filtration on Final Quality of Castings from Aluminium Alloy AlSi7Mg0,3, Archives of Foundry Engineering 11/ 1 pp. 5-10.

[16] O. Majidi, S. G. Shabestari, M. R. Aboutalebi (2007) Study of Fluxing Temperature in Molten Aluminum Refining Process, Journal of Materials Processing Technology 182. pp. 450-455. 